\title{
Coronavírus: consequências da pandemia no ensino superior
}

\author{
Coronavirus: consequences of the pandemic in higher education
}

\section{Coronavirus: consecuencias de la pandemia en la enseñanza superior}

Michelli Domingos da Silva ${ }^{1 *}$, Glória Cristina Araújo Soares ${ }^{2}$, Carla Mara Leandro Cardoso ${ }^{3}$, Thayanne Sa Bezerra Guerreiro ${ }^{3}$, Cyntia Costa Guimarães ${ }^{3}$, Giovanna Ribas Chicre ${ }^{3}$, Luciano Rodrigues Mendes de Siqueira ${ }^{3}$, Rebecca Pereira Seffair ${ }^{3}$, Nathany do Amaral Domingues ${ }^{3}$, Francilene de França Trindade ${ }^{4}$.

\section{RESUMO}

Objetivo: Analisar e descrever através da literatura sobre as consequências do coronavírus no ensino superior em tempos de pandemia. Métodos: Trata-se de uma pesquisa exploratória do tipo revisão integrativa. As bases de dados utilizadas foram: Google Acadêmico, Ministério da Saúde (MS), e Scientific Electronic Library Online (SCIELO). Como critério de inclusão foi estabelecido os artigos publicados em português e inglês, entre 2019 a 2021 e critérios de exclusão foram: Artigos cujos assuntos, títulos e objetivos não se encaixassem ao proposto, artigos repetitivos, em outros idiomas. Resultados: $O$ ano de 2020 foi atípico para todos. A pandemia de covid-19 acarretou uma série de consequências que afetam diversas áreas da vida, sendo uma delas a educação. Os alunos universitários em geral experimentaram o forte impacto da pandemia, e tiveram que recorrer a outras alternativas de aprendizado, em meio a anúncios e adiamentos de uma reabertura das aulas presenciais. Considerações Finais: As consequências da pandemia afetaram as atividades sociais, económicas e educativas e trouxeram consigo as dificuldades existentes. Ainda assim, muitos alunos que são desprovidos de recursos financeiros e tecnológicos não têm acesso as aulas disponibilizadas nas plataformas.

Palavras-chave: Coronavírus, Docência, Ensino a distância, Pandemia.

\begin{abstract}
Objective: Analyze and describe through literature about the consequences of coronavirus in higher education in times of pandemic. Methods: This is an exploratory research of the integrative review type. The databases used were: Google Scholar, Ministry of Health (MOH), and Scientific Electronic Library Online (SCIELO). As inclusion criteria it was established articles published in Portuguese and English, between 2019 and 2021 and exclusion criteria were: Articles whose subjects, titles and objectives did not fit the proposed, repetitive articles, in other languages. Results: The year 2020 was atypical for everyone. The covid-19 pandemic brought about a series of consequences affecting several areas of life, one of them being education. University students in general experienced the strong impact of the pandemic, and had to resort to other learning alternatives, amidst announcements and postponements of a reopening of face-to-face classes. Final Considerations: The consequences of the pandemic have affected social, economic, and educational activities and brought with them existing difficulties. Still, many students who are deprived of financial and technological resources do not have access to the classes made available on the platforms.
\end{abstract}

Key words: Coronavirus, Teaching, Education distance, Pandemic.

\section{RESUMEN}

Objetivo: Analizar y describir a través de la literatura las consecuencias del coronavirus en la educación superior en tiempos de pandemia. Métodos: Se trata de una investigación exploratoria de tipo revisión integradora. Las bases de datos utilizadas fueron: Google Académico, Ministerio de Salud (MOH) y Scientific Electronic Library Online (SCIELO). Como criterios de inclusión se establecieron artículos publicados en portugués e inglés, entre 2019 y 2021 y los criterios de exclusión fueron: Artículos cuyos temas, títulos y objetivos no se ajustaban a la propuesta, artículos repetitivos, en otras lenguas. Resultados: El año 2020 fue atípico para todos. La pandemia del covid-19 trajo consigo una serie de consecuencias que afectaron a varios ámbitos de la vida, uno de ellos la educación. Los estudiantes universitarios en general experimentaron el fuerte impacto de la pandemia, y tuvieron que recurrir a otras alternativas de aprendizaje, en medio de anuncios y aplazamientos de la reapertura de las clases presenciales. Consideraciones finales: Las

\footnotetext{
1 Universidad de Ciencias Empresariales y Sociales, Buenos Aires - AR.

*E-mail: michelliclarinha@hotmail.com

2 Singular Educacional, Manaus - AM.

3 Universidade Nilton Lins (UNL), Manaus - AM.

${ }^{4}$ Faculdade Metropolitana de Manaus (FAMETRO), Manaus - AM.
} 
consecuencias de la pandemia afectaron a las actividades sociales, económicas y educativas y trajeron consigo las dificultades existentes. Aun así, muchos estudiantes que carecen de recursos económicos y tecnológicos no tienen acceso a las clases que se ofrecen en las plataformas.

Palavras clave: Coronavirus, Enseñanza, Educación a distancia, Pandemias.

\section{INTRODUÇÃO}

Em 11 de março de 2020, a Organização Mundial da Saúde (OMS) admitiu a pandemia por covid-19. O primeiro estado confirmado com covid-19 no Brasil foi no estado de São Paulo em 26 de fevereiro de 2020, o Ministério da Saúde (MS) demorou muito em tomar uma atitude que pudesse evitar a contaminação da população por este vírus. Ainda assim, as proibições de voos vindos de outros países, não foram tão eficazes naquele momento, pois o vírus já tinha se espalhado em todas as regiões do país (SILVA MD, et al., 2021).

No Brasil, estima-se que as interrupções causadas pela pandemia da covid-19 podem acentuar as lacunas já existentes na educação. Sabe-se que o Ministério da Educação junto com os demais ministérios está passando por crises e trocas de gestores, e com isso os nossos alunos à mercê desta situação (GUSSO HL, et al., 2020).

À história da educação é representa nos três níveis de ensino (fundamental, médio e superior) há mais de 20 anos, e as aulas a distância não eram aceitas facilmente por alunos de aulas presenciais. Entretanto, as aulas a distância permanecem acirradas em meio a pandemia que se instaurou no mundo, onde poucos tem acesso à tecnologia deixando de ter um aprendizado de qualidade, por este motivo o coronavírus que trouxe consigo a sua presença na população acadêmica, o medo e a ansiedade de contaminar deixando muitos alunos apreensivos (ALVES L, 2020).

Outro problema nesta pandemia está sendo na saúde pública que afeta a população de forma agressiva, tirando o direito de ir e vir das pessoas. As medidas de isolamento e distanciamento social adotadas foram necessários para impedir que o vírus se propagarem de formas mais rápida e agressiva. Sabemos que 0 isolamento social em alguns estados não está surtindo o efeito esperado, entre eles o motivo causador seria financeiro, compreendemos que o isolamento é de extrema importância para tentar conter a propagação do coronavírus (AQUINO EML, et al., 2020).

Os docentes das universidades estão buscando melhorar a educação neste período, pode se dizer que a dificuldade existe por ambos, principalmente quando está relacionado há aulas remotas, pois muitos não têm equipamentos adequado para poder se comunicar, ex.: notebook, computadores, celulares e tablet, recursos esse que venha ajudar nas suas aulas diárias. No entanto, é admissível que esses esforços não sejam suficientes para fornecer a qualidade da educação oferecida na sala de aula remoto (RODRIGUES BR, et al., 2020).

As Instituições de Ensino Superior (IES), tiveram que se adaptar para minimizar os danos pedagógicos e riscos à saúde pública, se responsabilizando com a educação de nível superior dando qualidade e segurança, no que concerne as decisões de docentes quanto a sua forma de conduzir as disciplinas, o qual precisaria sofrer algumas alterações no plano de ensino/acadêmico (UNESCO, 2020a).

Durante as pesquisas, foram observadas algumas propostas adivindas de alguns reitores e pró-reitores de universidades, de como enfrentar as dificuldades e obstáculos impostos pela circunstância decorrente da pandemia, bem como de suportar as cobranças pedagógicas de forma leve e sem alvoroço, promovendo desta forma as condições viáveis e seguras para os docentes e discentes IES (RODRIGUES BR, et al., 2020).

O ensino online traz consigo um estigma de ser de característica inferior. A circunstância imposta pela pandemia determinou que, as IES tomassem as decisões mais apropriada para aquele momento sem grandes perdas nos processos de ensinar e aprender, de modo que os intermediários estejam comprometidos com os (docentes, discentes e funcionários), e que ambos estejam protegidos contra essa contaminação do coronavírus. (HODGES C, et al., 2020). Entretanto, essas aulas online vêm ajudar aqueles alunos que não tem acesso as aulas presenciais conforme a regulamentação do Ministério da Educação (MEC). Isso não 
quer dizer que as aulas remotas são de péssima qualidade, o problema é que muitos alunos não têm como acessar está aula por ausência de internet de boa qualidade e equipamentos que possam assessorar no seu aprendizado (VALENTE GSC, et al., 2020).

Sendo assim, as aulas remotas são de extrema necessidade para garantir e da continuidade ao ensino superior com qualidade. Alguns pesquisadores brasileiros e estrangeiros debateram entre sim como lidar com essa nova situação que se instalou no mundo e como será o ensino em meio a pandemia da covid-19. Objetivo do estudo é analisar e descrever através da literatura sobre as consequências do coronavírus no ensino superior em tempos de pandemia.

\section{MÉTODOS}

Trata-se de uma pesquisa exploratória do tipo revisão integrativa, iniciado a partir da elaboração do objetivo da pesquisa. Para o levantamento dos artigos, realizou-se uma busca de artigos científicos, em base de dados informatizados, além de buscas anuais com referências, as bases de dados foram: Google Acadêmico, Ministério da Saúde (MS) e (SCIELO). Foram utilizados, para busca dos artigos, os seguintes descritores de Saúde: Coronavírus, Docência, Ensino a Distância, Pandemia, Tecnologia Digital.

Como critério de inclusão, foi estabelecido os artigos publicados em português e inglês, entre 2019 a 2021 , com tema e resumos que interpretassem a temática referente a essa revisão. Já os critérios de exclusão foram: Artigos cujos assuntos, títulos e objetivos não se encaixassem ao proposto, artigos repetitivos, em outros idiomas. A seleção inicial dos trabalhos, ocorreu pela leitura dos títulos e resumos de todos os trabalhos encontrados. Seguindo os critérios de inclusão e exclusão, a partir da leitura dos títulos e resumos dos 50 artigos, e a seguir foram selecionados 5 artigos conforme (Figura 1).

Figura 1 - Fluxograma Síntese dos artigos selecionados.

Artigos Identificados Durante a busca da revisão

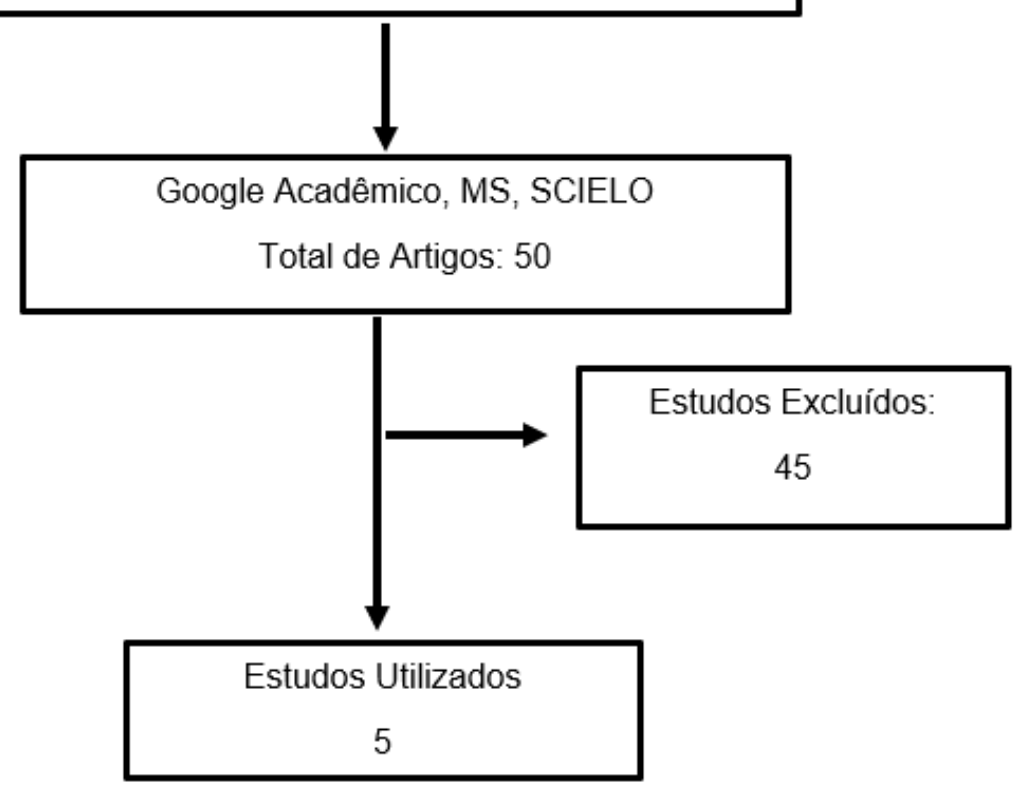

Fonte: Silva MD, et al., 2021.

De acordo com o Quadro 1, foi observado que os artigos abordados têm em comum a dificuldade das aulas remotas, além de serem analisados em diferentes aspectos ao ensino e aprendizagem em tempos de pandemia. Os artigos listados vêm confirmar que as plataformas disponíveis para o ensino remoto demonstraram níveis de adequação baixo, por não terem acesso à internet e enfrentando com muitas incertezas. 
Quadro 1 - Síntese dos artigos sobre consequências da pandemia no ensino superior no período de 2019-2021.

\begin{tabular}{|c|c|c|c|c|}
\hline Autor/Ano & Título & $\begin{array}{c}\text { Bases } \\
\text { Metodologia }\end{array}$ & Resultados & Conclusão \\
\hline $\begin{array}{c}\text { SILVA AC e } \\
\text { BRÊTAS AA, } \\
2021 .\end{array}$ & $\begin{array}{l}\text { Saúde estudantil } \\
\text { universitária e as } \\
\text { tecnologias virtuais: } \\
\text { relato de experiência }\end{array}$ & $\begin{array}{l}\text { O estudo, de } \\
\text { cunho } \\
\text { qualitativo }\end{array}$ & $\begin{array}{l}\text { Foi possível perceber, por meio de seus relatos que: tanto } \\
\text { em } 2011 \text { quanto em } 2020 \text { tiveram dificuldades em } \\
\text { conhecer e aprender essas tecnologias, bem como } \\
\text { estudar sozinho em frente a um computador o que gerou } \\
\text { certo estresse e ansiedade. Esse desconforto, como } \\
\text { esperado, foi maior nos estudantes de } 2020 \text { proveniente } \\
\text { do uso compulsório das salas virtuais em decorrência da } \\
\text { COVID-19. }\end{array}$ & $\begin{array}{l}\text { Os estudantes de cursos presenciais, por } \\
\text { desconhecerem as salas virtuais, tendem a refutá-las. } \\
\text { Por isso, é necessário inserir atividades que busquem a } \\
\text { empatia com essas tecnologias para diminuir a } \\
\text { ansiedade. }\end{array}$ \\
\hline $\begin{array}{l}\text { ANDRADE } \\
\text { DPC e } \\
\text { MONTEIRO } \\
\text { MI, } 2019 .\end{array}$ & $\begin{array}{c}\text { Educação Híbrida: } \\
\text { abordagens práticas no } \\
\text { Brasil }\end{array}$ & $\begin{array}{l}\text { Pesquisa } \\
\text { qualitativa, sob } \\
\text { a metodologia } \\
\text { exploratória }\end{array}$ & $\begin{array}{l}\text { A educação enfrenta desafios em seus níveis de ensino e } \\
\text { modalidades. O Ensino Híbrido surge oferecendo uma } \\
\text { personalização do ensino tradicional até então vigente, } \\
\text { mesclando o que há de melhor no ensino tradicional aos } \\
\text { novos métodos de ensino, utilizando as Tecnologias } \\
\text { digitais de informação e comunicação (TDIC). }\end{array}$ & $\begin{array}{l}\text { Foi possível concluir que a metodologia híbrida se } \\
\text { apresenta como um método eficaz para o rompimento } \\
\text { de práticas tradicionais em contextos de aprendizagem. }\end{array}$ \\
\hline $\begin{array}{l}\text { FAVERO M } \\
\text { et al., } 2020\end{array}$ & $\begin{array}{l}\text { Ensino Superior em } \\
\text { Saúde em tempos de } \\
\text { Pandemia: reflexões } \\
\text { emergentes }\end{array}$ & $\begin{array}{l}\text { Revisão crítica, } \\
\text { de caráter } \\
\text { descritivo - } \\
\text { discursivo }\end{array}$ & $\begin{array}{l}\text { Com base no panorama educacional apresentado e } \\
\text { vivenciado em todos os níveis da educação neste tempo } \\
\text { de pandemia emerge uma preocupação em relação a } \\
\text { forma como as instituições de ensino superior estão } \\
\text { interpretando } \\
\text { essas mudanças e preparando o futuro do ensino superior } \\
\text { no Brasil, em especial dos cursos da área da saúde. }\end{array}$ & $\begin{array}{l}\text { O uso imediato e a aplicação das tecnologias para } \\
\text { enfrentar este desafio global de saúde pública estão } \\
\text { transformando de forma irreversível o ensino em saúde } \\
\text { e em outras áreas em todo o mundo. O contexto } \\
\text { pandêmico sinaliza, portanto, a necessidade de estudar } \\
\text { as iniciativas da comunidade científica para adaptação } \\
\text { do ensino e pesquisa, possibilitando discussões e } \\
\text { reflexões em relação ao desenvolvimento de modelos } \\
\text { educacionais em EaD com potencial para se consolidar } \\
\text { no futuro pós crise. }\end{array}$ \\
\hline $\begin{array}{l}\text { OLIVEIRA } \\
\text { SS, et al., } \\
2020 .\end{array}$ & $\begin{array}{l}\text { Educar na incerteza e na } \\
\text { urgência: implicações do } \\
\text { ensino remoto ao fazer } \\
\text { docente e a reinvenção } \\
\text { da sala de aula }\end{array}$ & $\begin{array}{c}\text { Estudo } \\
\text { netnográfico }\end{array}$ & $\begin{array}{l}\text { Este texto propõe uma reflexão sobre os desafios } \\
\text { enfrentados por professores da Educação Básica, ao } \\
\text { vivenciarem a experiência com o ensino remoto, mediado, } \\
\text { especialmente, pelas tecnologias digitais (TD), dada a } \\
\text { necessidade de distanciamento social, provocado pela } \\
\text { covid-19. }\end{array}$ & $\begin{array}{l}\text { Este estudo toma como base autores que discutem } \\
\text { sobre tecnologias digitais e formação docente, prática } \\
\text { pedagógica potencializada pelas tecnologias digitais, } \\
\text { ensino remoto e desafios à educação, a partir de artigos } \\
\text { e vídeos já socializados na internet, pelos sites e redes } \\
\text { sociais. }\end{array}$ \\
\hline $\begin{array}{l}\text { AMARAL E e } \\
\text { POLYDORO } \\
\text { S, } 2020 .\end{array}$ & $\begin{array}{l}\text { Os desafios da mudança } \\
\text { para o ensino remoto } \\
\text { emergencial } \\
\text { na graduação na } \\
\text { UNICAMP - Brasil }\end{array}$ & $\begin{array}{l}\text { Revisão } \\
\text { qualitativa }\end{array}$ & $\begin{array}{l}\text { Este artigo relata a resposta da Unicamp à pandemia } \\
\text { Covid-19 no âmbito da Graduação. Com a suspensão das } \\
\text { atividades presenciais e a adoção do ensino remoto } \\
\text { emergencial em março de } 2020 \text {, cada unidade acadêmica } \\
\text { propôs seu plano de ação, mantendo disciplinas remotas } \\
\text { total ou parcialmente. }\end{array}$ & $\begin{array}{l}\text { Finalmente, o novo semestre e o encerramento do ano } \\
\text { letivo ainda serão enfrentados com muitas incertezas, } \\
\text { incluindo quando será possível retomar as atividades } \\
\text { presenciais e com que quantidade de pessoas nos } \\
\text { campi. }\end{array}$ \\
\hline
\end{tabular}

Fonte: Silva MD, et al., 2021. 


\section{DISCUSSÃO}

Gomes F e Ferreira GA (2020), comenta que as empresas e instituições de ensino se viram obrigadas a migrar para o ambiente virtual, um instrumento de extrema importância para o universo acadêmico que tem sido muito empregada como uma forma de reestruturar nossa relação por videoconferências. Por este motivo, os acontecimentos foram ocupados em espaços virtuais.

De acordo com Dias E e Pinto FCF (2020), o encerramento das aulas presencias nas universidades/faculdades pôs o ensino superior, em evidência com o fechamento de suas atividades presenciais. Muitos docentes não conseguem lidar com a nova tecnologia que está no mercado a décadas, e colocar as aulas tradicionais na internet e achar que tudo vai continuar como antes isso é impossível.

As aulas remotas têm que ser de qualidade e bem preparadas, os discentes que possam participar dessas atividades remotas através de um sistema de acompanhamento e avaliação onde os resultados são totalmente diferentes dos tradicionais. Tecnologias para isso existem, no entanto, algumas instituições brasileiras estão preparadas para usá-las (DIAS E e PINTO FCF, 2020).

A maior parte do corpo docente, principalmente das entidades de ensino público, algumas são avessar a trabalhar remotamente com os seus alunos. A Educação à Distância (EAD), no entanto, nos últimos anos se expandiu, trazendo consigo ganhos para as universidades privadas, depois que o crédito educacional ficou mais rígidos, os recursos que o governo proporcionava ficou mais difícil de obter. Ainda assim, a procura pela EAD neste exato momento de pandemia é a melhor do mercado educacional de ensino superior (MANSUR PF, 2020).

A educação corriqueira traz consigo, olho no olho, é imprescindível quando o docente pode trabalhar com um número menor de alunos. A maior dificuldade é no ensino superior, em suprir as necessidades de equipamentos como: computador, notebook, tablet, smartphone e acesso à internet de qualidade para dá continuidade ao aprendizado, a flexibilidade ao acesso e recursos pedagógicos são escassos na maioria das universidades/faculdades, essas plataformas de ensino podem contribuir para diminuir as desvantagens de quem mora longe, e de quem precisa trabalhar mais não ganha o suficiente para manter os estudos nas universidades tradicionais (ALVES L, 2020).

Para Gusso HL, et al. (2020), comenta que a implementação do ensino remoto às pressas, é possível que os obstáculos com o tempo, planejamento, treinamento e suporte técnico para ofertar as aulas de forma remota, trouxe consigo comprometimento e qualidade do ensino superior. Ainda que, não seja visível os efeitos do ensino remoto, é admissível que as consequências sejam percebidas nas universidades/faculdades aquelas que optaram por dá continuidade ao ensino a distância.

Alguns docentes observaram o baixo desempenho dos acadêmicos estão presentes no seu cotidiano; acréscimo do fracasso universidades; acréscimo da perspectiva de evasão do ensino superior; desgaste dos docentes, que estiveram sobrecarregados pelas múltiplas atividades e pelos desafios de lidar com a tecnologia a fim de promover o ensino de qualidade (GUSSO HL, et al., 2020).

Appenzeller S, et al. (2020), relata que os principais problemas identificados foram internet instável e/ou acesso exclusivo por redes móveis, que muitas vezes estão sobrecarregadas por terem milhões de usuários ao mesmo tempo. As atividades com maiores dificuldades tantos para os docentes e discentes era através das plataformas como Google Meet e Zoom, seguidos por acesso a plataformas digitais e aplicativos de imagem.

De acordo com Al Samaraee A, et al. (2020), no início das aulas a maior proporção de alunos queixosos, era porque não tinha acesso a plataforma e as atividades anexadas na sala Google. A grande maioria dos alunos, mencionou que acompanhava as aulas por computadores, notebooks e celulares, ainda assim, alguns desses aparelhos eram compartilhados com outros membros da família atrapalhando o acesso dos mesmos na plataforma.

Burki TK (2020), comenta que os materiais disponibilizados pela Pró-Reitoria de Graduação o acesso livre aos computadores da instituição com acesso limitado à internet. Muitos dos professores tiveram que arcar 
com os custos da internet móvel do seu celular para dá conta das suas atribuições. Os alunos não tinham acesso a esses recursos por está proibido a entrada do mesmo na instituição de ensino.

Para Alves L (2020), as atividades liberadas através do Google sala de aula, foram imprescindíveis no acompanhamento desses alunos ao identificar as suas necessidades de materiais pedagógicos precocemente. Com isso, observamos que no primeiro semestre houve pouquíssima desistência com relação ao semestre atípico, por conta da política instituída pela universidade neste momento de pandemia.

Senra VBC e Silva MS (2020), relata que o objetivo principal do ensino remoto não é recriar um novo modelo educacional e sim aprimorar o que temos no mercado, mas fornecer acesso provisório aos conteúdos e apoios educacionais que venha tornar mínimo possível os efeitos do isolamento social nessa metodologia.

Segundo Joye CR, et al. (2020), os princípios do ensino remoto seguem conforme os da educação presencial, além disso, seguindo as normas do modelo expositivo tradicional no qual o aluno se torna um mero repositório de informações, para facilitar seus acessos nas plataformas de ensino.

Brasil (2020), confirma o parecer do Conselho Nacional de Educação e do Ministério da Educação do Brasil, seguiu a mesma linha dos outros países e tomou para se as dificuldades causadas pela pandemia. Adotou algumas medidas para que os alunos que não tivessem acesso as aulas remotas, recebesse as matérias de estudo impressos e em momentos oportunos as aulas presenciais será retomada com algumas mediadas de segurança para todos.

Já UNESCO (2020), comenta que precisamos repensar o futuro da Educação, incluindo uma articulação apropriada entre o EaD e o Ensino presencial. Por isso que, alguns alunos no Brasil não têm acesso a computadores, celulares ou à Internet de qualidade, a nossa realidade é vivenciada todos os dias pelas secretarias de Educação de Estados e Municípios no atual cenário.

O retorno às atividades de ensino remoto durante a pandemia requer um distanciamento físico para evitar a disseminação do vírus, entre os discentes e docentes onde envolve múltiplas decisões, defendidas no conceito da IES. As Universidades estão se adequando tanto as tecnologias e também as aulas tradicionais, em que todos os envolvidos passem por um processo de ensino, onde os estudantes e professores, tenha 0 livre acesso a estes recursos tecnológicos (MELO I, et al., 2020).

Para que isso venha a acontecer é necessário que todos os estudantes e professores estejam em condições de saúde física, psíquica e que tenha destreza em lidar com a tecnologia, para tal a realização é necessário ter as atividades de forma remota. Ainda assim, o ensinar ou transmitir o conteúdo é basicamente, repassar para os discentes as informações inerentes ao curso. Isso poderá acontecer nas aulas remotas em modo síncrono ou assíncrono e permitindo basicamente as decisões como o tipo de aplicativo a ser utilizado para transmitir aulas pelo Google Meet, Zoom entre outras plataformas a ser apresentadas pelas instituições de ensino (GERALDO G, 2020).

Jimenez-Sanchez C (2020), relata que a desigualdade na distribuição e acesso à internet torna o ensino remoto mais exclusivo do que o presencial, incomodando com inúmeras contestações de como fazer e superar este obstáculo no momento. Ainda assim, estar ou não conectado a uma plataforma onde muitos dos alunos necessitam de um diálogo claro, que possam proporcionar os encontros semanais e presenciais de forma remota.

Para que isso venha surtir um efeito positivo nas aulas remotas, temos que estar atentos ao nível de ansiedades dos alunos e professores, evitando o máximo possível de pressão em cima deles, por causa do distanciamento social e coletivo, terá que ser observado como está empatia dos mesmos depois de todos esses acontecimentos. Entretanto, o distanciamento físico trouxe consigo mudanças de vida da população acadêmica, seja ela sobre os últimos acontecimentos mundiais, econômicos e sociais que refletem na vida da população (JIMENEZ-SANCHEZ C, 2020).

De acordo Moreira JA, et al. (2020), as atividades síncronas foram desenvolvidas durante o as aulas online, necessitando de um feedback imediato, com o intuito de promover o conhecimento nas atividades com os estudantes, ou para avaliar o aprendizado. Já as sessões assíncronas correspondem à essência da educação 
online, pois não necessita de uma confluência do docente e de seus discentes no espaço e no tempo, harmonizando maior flexibilidade do método educativo.

A situação atual no Brasil, vem comprovar a necessidade de atividades assíncronas que juntam uma maior quantidade de discentes, de uma só vez e ao mesmo tempo. Essas aulas estão disponíveis em tempo real, é recurso vital para dá continuidade ao ensino remoto e de qualidade. Sabendo dessa necessidade os docentes sofre por uma pressão dos seus gestores, para busca alternativas para a prática pedagógica remoto, e o uso das plataformas digitais poderá ser mais frequente ao decorrer dos próximos anos, pois, mesmo em períodos de normalidade ou pós-pandemia, essas plataformas de acesso são utilizadas por variados públicos, incluindo os universitários (MOREIRA JA, et al., 2020).

Brasil (2018), confirma que a educação é direito de todos e dever do Estado e da família. Não levar em conta as desigualdades sociais e econômicas do nosso país, os sistemas de educação brasileiros impossibilitam o alcance dos desígnios impostos pela pandemia. A crise na saúde está em evidencias em todos os estados, automaticamente respingou na educação. As IES contribuem para que nada disso venha mudar, tornando-se mais vulnerável o trabalho dos docentes, que em meio à tantas dúvidas têm sua saúde e categorias de trabalho se tornando motivo de desapontamento e esgotamento físico e mental.

Para Souza DG e Miranda JC (2020), esse novo panorama do ensino, passa a acontecer por meio de uma plataforma virtual, com docentes e discentes sem formação e sem domínio das ferramentas digitais. Ainda assim, muitos vivem em regiões sem acesso à internet ou com conexão instável. Vale ressaltar que há casos de docentes e discentes que não possuem computador ou aparelhos celulares que tenha internet móvel, as vezes é a única forma de acesso à internet, e sabemos que os pacotes de dados são limitados de acordo com plano de acesso à internet.

A cobrança de uma preparação das aulas, caracteriza desconforto e ao mesmo tempo temos que fazer o acolhimento desses estudantes por diferentes meios de comunicação, faz com que o docente esteja conectado ao trabalho a todo momento, até mesmo fora do horário regular e nos fins de semana. Soma-se a esta sobrecarga profissional, que se tornou a predominante neste período pandêmico, e venha acarretar insegurança gerada entre os discentes e docentes (SOUZA DG e MIRANDA JC, 2020).

Dias GN, et al. (2020), conta que essa situação vem provocando grande sobrecarga emocional, e acarretando um aumento do estresse, da ansiedade, da insônia e outros sintomas pertinentes à saúde mental. Um dos grandes desafios enfrentados pelo ensino remoto, diz respeito à efetividade do conhecimento cientifico e técnico, uma vez que estiver conectado não significa que esteja online. Alguns docentes geralmente solicitar que os alunos desliguem a sua câmera para melhorar a conexão da internet.

Durante o andamento do aprendizado, o aluno poderá desenvolver ferramentas paralelas às atividades propostas pelo professor. Deste modo, não posso garantir que o aluno esteja na aula e nem tão pouco posso afirmar que eles estejam presentes no ambiente virtual onde são desenvolvidas as atividades síncronas e assíncronas sugeridas pelo docente. O ensino remoto, comprovou as desigualdades sociais. Muitos discente tem dificuldades de acesso ou sem acesso à internet não conseguem conectar-se às plataformas virtuais de ensino. Onde já foi com provado por alguns pesquisadores que o acesso a essas tecnologias é privilégio de poucos alunos (CÉSAR PAB, et al., 2020).

Segundo Souza DG e Miranda JC (2020), a cada 10 pessoas, quatro não tem acesso à internet de qualidade no Brasil. Por outro lado, os pais de estudantes, profissionais da educação e especialistas em saúde pública, em sua maioria, avessos ao retorno das atividades acadêmicas, que consideram prematuro e perigoso no atual cenário, sem o controle da covid-19, sem vacinação suficiente para a população, neste sentido é imprescindível alertar a sociedade e órgãos gestores educacionais das ações e dificuldades provenientes da pandemia.

Cesar PAB, et al. (2020), relata que o distanciamento social é necessário, para que a população não venha disseminar a covid-19, isso acarretara em um impacto a saúde mental de todos, em um cotidiano atípico, e difícil de manter uma rotina provisória. Essa soma desses fatores tem gerado emoções contraditórias, desde o medo do contágio, ansiedade e estresse diante de uma nova doença sobre a qual ainda pouco se admite. 
Para Dias GN, et al. (2020), temos que trabalhar na prevenção, além do fato que não temos remédios suficientes para combater e controlar a covid-19. Ainda assim, os leitos disponíveis nos hospitais para o tratamento da covid-19 não são suficientes para tratar e cuidar da população que necessitam de cuidados especializados. Uma vez contaminado tem que ficar no isolamento, pois é um dos métodos preventivos eficaz associado à lavagem das mãos e o uso de máscara. Para que isso venha surtir o efeito positivo, temos que continuar com as restrições necessária para que este vírus venha ser disseminado ou controlado no nosso país.

\section{CONSIDERAÇÕES FINAIS}

As consequências da pandemia afetaram as atividades sociais, económicas e educativas, trouxeram consigo as dificuldades existentes. Ainda assim, muitos alunos que são desprovidos de recursos financeiros e tecnológicos não têm acesso as aulas disponibilizadas nas plataformas. Sabemos que a desigualdade social e econômica existe, e neste momento temos que trabalhar para que todos façam parte dessa nova era. E que as dificuldades por acesso as aulas remotas venham diminuir com a sensibilidades dos gestores que estejam a frente podendo disponibilizar as aulas impressas para aqueles que não tem acesso à internet.

\section{REFERÊNCIAS}

1. ALVES L. Educação remota: entre a ilusão e a realidade. Interfaces Científicas-Educação, 2020; 8(3): 348-365.

2. AI SAMARAEE A. The impact of the COVID-19 pandemic on medical education. Br J Hosp Med (Lond), 2020; 81(7):14.

3. AMARAL E, POLYDORO S. Os desafios da mudança para o ensino remoto emergencial na graduação na UnicampBrasil. Linha Mestra, 2020; 41: 52-62.

4. ANDRADE DPC, MONTEIRO MI. Educação Híbrida: abordagens práticas no Brasil. Revista Eletrônica Científica Ensino Interdisciplinar, 2019; 5(14): 250-264.

5. APPENZELLER S, et al. Novos Tempos, Novos Desafios: Estratégias para Equidade de Acesso ao Ensino Remoto Emergencial. Rev. bras. educ. med., 2020; 44(supl. 1): e155.

6. AQUINO EML, et al. Medidas de distanciamento social no controle da pandemia de COVID-19: potenciais impactos e desafios no Brasil. Ciênc. saúde coletiva, 2020; 25(supl.1): p. 2423-2446.

7. BRASIL. 2020. In: Portaria № 345, de 19 de Março De 2020. Brasília: Ministério da Educação. Disponível em: https://www.in.gov.br/en/web/dou/-/portaria-n-345-de-19-de-marcode2020248881422? inheritRedirect=true\&redirect=\%2Fweb\%2Fguest\%2Fsearch\%3FqSearch\%3DPortaria\%252034 5\%2520 de \%252019\%2520de\%2520mar\%25C3\%25A70\%2520de\%25202020. Acesso em: 12 de mar. 2021.

8. BURKI TK. COVID-19: consequences for higher education. Lancet Oncol. 2020; 21(6):758.

9. CÉSAR PAB, et al. The Emotional Impact and its Relations in the Built Environment with the Traveler and Resident Confrontation in Times of Pandemic [and after]. Rosa dos Ventos, 2020; 12.

10. DIAS E, PINTO FCF. A Educação e a Covid-19. Ensaio: aval. pol. públ. Educ., Rio de Janeiro, 2020; 28(108): 545554.

11. DIAS GN, et al. Retorno às aulas presenciais no sistema educacional do estado do Pará Brasil: Obstáculos e desafios durante a epidemia de COVID - 19(Sars-Cov-2). Brazilian Journal of Development, 2020; 6.

12. FAVERO M, et al. Ensino Superior em Saúde em tempos de Pandemia: reflexões emergentes. Brazilian Journal of Development, 2020; 6(10): 79345-79353.

13. GERALDO G, et al. Discussões Sobre as Consequências da Pandemia Covid-19 no Ensino e na Aprendizagem, na Graduação, EM 2020. XXI Encontro Nacional de Educação (ENACED) e I Seminário Internacional de Estudos e Pesquisas em Educação (SIEPEC), 2020; 1.

14. GOMES F, FERREIRA GA. educação na pandemia do novo coronavírus: uma excepcionalidade ou uma prioridade?. Itinerarius Reflectionis, 2020; 16(1): 1-24.

15. GUSSO HL, et al. Ensino Superior em Tempos de Pandemia: Diretrizes a Gestão Universitária. Educ. Soc., Campinas, 2020; 41 : e238957.

16. HODGE C, et al. The difference between emergency remote teaching and online learning. Educause Review, Washington, 2020.

17. JIMENEZ-SANCHEZ C. Impacto de la Pandemia por SARS-CoV2 sobre la Educación. Educare, Heredia, 2020; 24(supl. 1): 1-3.

18. JOYE CR, et al. Distance Education or Emergency Remote Educational Activity: in search of the missing link of school education in times of COVID-19. Research, Society and Development, 2020, 9(7): e521974299, 1-29.

19. MANSUR PF. Implementação de gestão de educação a distância na graduação do programa UAB/UNB: um estudo de caso. 2020.

20. MELO I, et al. As Consequências da Pandemia (Covid-19) na Rede Municipal de Ensino: Impactos e Desafios. 2020. 
21. MOREIRA JA, et al. Transitando de um ensino remoto emergencial para uma educação digital em rede, em tempos de pandemia. Dialogia, 2020; 351-364.

22. OLIVEIRA SS, et al. Educar na incerteza e na urgência: implicações do ensino remoto ao fazer docente e a reinvenção da sala de aula. Interfaces Científicas - Educação, 2020, 10(1): 25-40.

23. SENRA VBC, SILVA MS. A educação frente à pandemia de COVID-19: atual conjuntura, limites e consequências. Brazilian Journal of Development, 2020; 6(12): 101771-101785.

24. SILVA AC, BRÊTAS AA. Saúde estudantil universitária e as tecnologias virtuais: relato de experiência. Revista Eletrônica Acervo Saúde, 2021; 13(2): e6090.

25. SILVA MD, et al. Panorama clínico dos profissionais de saúde em meio a pandemia na Capital do Amazonas. Brazilian Journal of Health Review, 2021; 4(1): 2461-2473.

26. SOUZA DG, MIRANDA JC. Desafios da implementação do ensino remoto. Boletim de Conjuntura (BOCA), 2020; 4(11): $81-89$

27. RODRIGUES BB, et al. Aprendendo com o Imprevisível: Saúde Mental dos Universitários e Educação Médica na Pandemia de Covid-19. Rev. bras. educ. med., 2020; 44 (supl.1): e149.

28. UNITED NATIONS EDUCATIONAL, SCIENTIFIC AND CULTURAL ORGANISATION (UNESCO). A Comissão Futuros da Educação da Unesco apela ao planejamento antecipado contra o aumento das desigualdades após a COVID-19. Paris: Unesco, 16 abr. 2020. Disponível em: https://pt.unesco.org/news/comissao-futuros-da-educacaoda-unesco-apela-ao-planejamento-antecipado-o-aumento-das. Acesso em: 13 mar 2021.

29. UNITED NATIONS EDUCATIONAL, SCIENTIFIC AND CULTURAL ORGANISATION (UNESCO). COVID-19 Educational disruption and response. Paris: Unesco, 2020a. Disponível em: http://www.iiep.unesco.org/en/covid-19educational-disruption-and-response-13363. Acesso em: 13 mar 2021.

30. VALENTE GSC, et al. O ensino remoto frente às exigências do contexto de pandemia: Reflexões sobre a prática docente. Research, Society and Development, 2020; 9(9): e843998153. 